\title{
Human parvovirus infection in early rheumatoid and inflammatory arthritis
}

\author{
B J COHEN ${ }^{1}$ M M BUCKLEY, ${ }^{1}$ J P CLEWLEY ${ }^{1}$ V E JONES ${ }^{2}$ A H PUTTICK ${ }^{2}$ \\ AND R K JACOB Y
}

From the ${ }^{1}$ PHLS Virus Reference Laboratory, Central Public Health Laboratory, Colindale Avenue, London; and the ${ }^{2}$ Postgraduate Medical School, University of Exeter, Royal Devon and Exeter Hospital (Wonford), Exeter

SUMMARY Evidence of recent infection with human parvovirus B19 (HPV) was found in two patients with early rheumatoid arthritis (RA) and in four patients with acute inflammatory arthritis (IA). Both of the patients with RA but only one of the four patients with IA carried RA associated haplotypes. No evidence of persistent infection with HPV was found, but evidence of past infection with HPV was significantly more common in patients with RA than in controls. The results confirm the arthritogenic potential of HPV and are consistent with the hypothesis that rheumatoid arthritis may develop in a genetically predisposed patient after an arthritogenic insult such as an HPV infection.

Key words: human parvovirus B19, MHC haplotypes.

Parvoviruses have recently been suggested as a cause of human joint disease. A parvovirus designated RA-1 was isolated from the synovial tissue of a patient with rheumatoid arthritis and shown to be pathogenic in newborn mice ${ }^{1}$ though its involvement in human disease has not been confirmed. A second parvovirus, designated human parvovirus B19 (HPV), which is antigenically distinct from RA-1, has been identified as a cause of acute arthropathy, particularly in women. ${ }^{23}$ The most common clinical manifestation of HPV infection, however, is erythema infectiosum (fifth disease), an exanthematous infection of childhood. ${ }^{4}$ This is a mild illness without constitutional upset in children, but in adults it is frequently complicated by arthralgia, and joint swelling has been observed in up to $60 \%$ of adult cases. ${ }^{5}$ It is now apparent that HPV infection in adults may present with joint symptoms in the absence of the rash which characterises the infection in children. ${ }^{2} 3$

Arthropathy associated with HPV infection usually takes the form of a peripheral, symmetrical polyarthritis of sudden onset. It is relatively benign

Accepted for publication 18 April 1986.

Correspondence to $\mathrm{Dr}$ B J Cohen, PHLS Virus Reference Laboratory, Central Public Health Laboratory, Colindale Avenue, London NW9 5HT. and most cases resolve within a few weeks. ${ }^{23}$ This has been confirmed by studying the effect of HPV on human volunteers. ${ }^{6}$ A few HPV infected patients have more persistent joint involvement lasting months or even years, and their signs and symptoms would fulfil the diagnostic criteria for definite rheumatoid arthritis (RA). ${ }^{7}$ In addition, a protracted case of HPV arthropathy has been described where there was an associated rise of rheumatoid factor to high titre. ${ }^{8}$ These findings raise the possibility that HPV might be an aetiological trigger in some cases of rheumatoid arthritis.

On the other hand, evidence seeming to exclude a role for HPV in rheumatoid arthritis has been obtained from a serological study in which antibody to HPV was detected in rheumatoid arthritis patients at a frequency that was not significantly different from that in healthy adults. ${ }^{9}$ Antibody in this study, however, was detected by the relatively insensitive method of counterimmunoelectrophoresis, and a further study of rheumatoid arthritis and HPV infection would seem to be warranted making use of more sensitive assays, including radioimmunoassays for HPV specific IgM and IgG and HPV antigen ${ }^{10}$ and 'dot blot' hybridisation for HPV DNA. ${ }^{11}$

In a preliminary investigation with these newer 


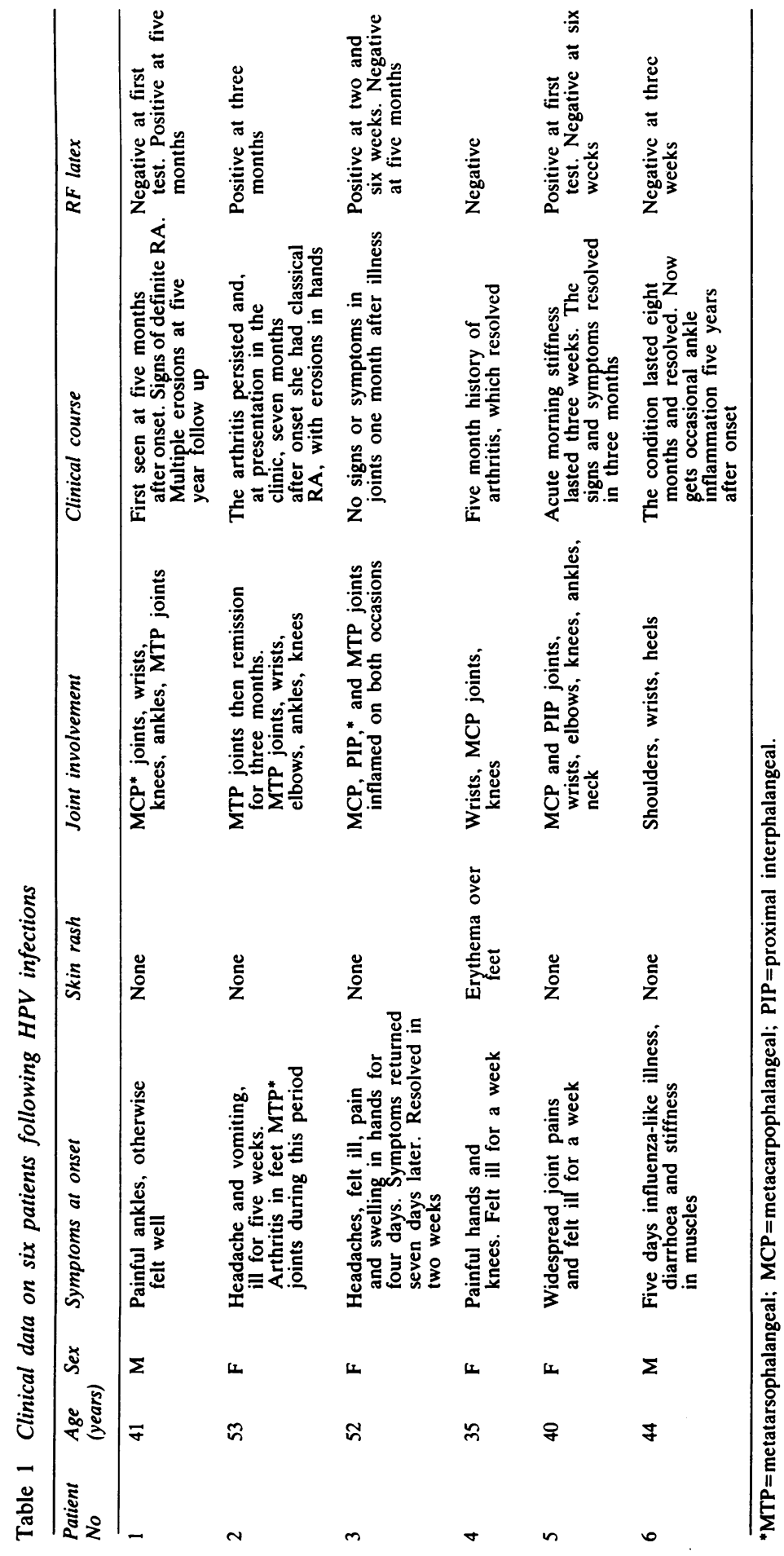


methods Jones and colleagues described two patients with recent $H P V$ infection, one with early RA and the other with inflammatory arthritis (IA). ${ }^{12}$ The patient with RA carried HLA antigens associated with a risk of developing this disease; the patient with IA did not. We now report a study in which we have sought evidence of HPV infection in a series of patients with early rheumatoid arthritis. Patients with acute inflammatory arthritis were also examined as were controls matched for age and sex.

\section{Patients and methods}

PATIENTS AND SPECIMENS

Serial serum specimens were examined retrospectively from 39 patients with definite or classical $\mathrm{RA}^{7}$ and from 37 IA patients with unclassified inflammatory polyarthritis or arthralgias, or both, who attended the Royal Devon and Exeter Hospital from 1977 to 1985 . Patients were included in the survey if they had a serum sample collected within five months of onset of arthritic symptoms, and initially only the earliest available specimen was examined. Where evidence of recent HPV infection was obtained, serial serum specimens collected during the course of the illness were also examined. The controls comprised single serum samples from 69 hospital staff and volunteers resident in Devon and donated over the same period as the patients' sera. Synovial fluids taken within five months of onset of symptoms were available from 19 of the patients with RA and from nine of the patients with IA. Fifty of the patients had been included in earlier studies of immune complexes in early arthritis. ${ }^{13} 14$

\section{METHODS}

Serum specimens were tested for anti-HPV IgM and anti-HPV IgG by radioimmunoassay with monoclonal antibodies. ${ }^{10}$ Synovial fluids were examined for HPV antigen by radioimmunoassay ${ }^{10}$ and for HPV DNA by the 'dot blot' hybridisation assay. ${ }^{11}$ Synovial fluids from anti-HPV IgG seropositive patients were tested for anti-HPV IgG.

Specimens from the arthritic patients were examined by Dr R J C Hart, Public Health Laboratory, Exeter, for evidence of recent infection with influenza $\mathbf{A}$ and $\mathbf{B}$, parainfluenza, Mycoplasma pneumoniae, adenovirus, cytomegalovirus, varicellazoster, mumps, and rubella.

Patients were examined for HLA-A, B, and DR antigens by a microcytotoxicity assay with antisera from the Exeter and Guy's Hospital tissue typing laboratories. Complement alleles of $\mathrm{Bf}, \mathrm{C} 4 \mathrm{~A}$, and $\mathrm{C} 4 \mathrm{~B}$ and the red cell isoenzyme glyoxalase-1 were determined by high voltage electrophoretic methods ${ }^{15}$ based on techniques described by Awdeh and Alper ${ }^{16}$ and Kömpf et al. ${ }^{17}$
Rheumatoid factor (RF) to human IgG was measured by latex agglutination with RapiTex $\frac{\mathrm{C}}{\omega}$ (Behringwerke AG, Marburg, FDR).

\section{Results}

Most of the 76 arthritic patients had similar symptoms initially whether or not they developed RA subsequently, and the polyarthritis associated with HPV could not be distinguished from that described by other patients in this study. First symptoms $\vec{\circ}$ included nerve entrapment, morning stiffness, and painful joints with or without swelling. Any of the peripheral joints could be involved. A summary of clinical presentation by the six patients with evi- ? dence of HPV infection is given in Table 1. of

IgM specific for parvovirus, indicating recent $\overrightarrow{0}$ HPV infection, was found in two patients with early rheumatoid arthritis and in four patients with $N$ inflammatory arthritis. It was not found in any of the 을 controls. The evolution of the anti-HPV IgM responses in the six patients is illustrated in Fig. 1, O which also shows the anti-HPV IgG responses and $\stackrel{0}{0}$ RF titres. The presence of high levels of anti-HPV $\mathbb{\Phi}$ IgG which gradually fell supports the diagnosis of $\vec{\bullet}$ recent HPV infection. The highest levels of ants HPV IgM were found in the patients with inflamma tory arthritis, but these were first tested early: on two, three, and six weeks after onset of symptoms. The levels of anti-HPV IgM were much lower in the patients with early rheumatoid arthritis, but they were first tested 12 and 20 weeks after onset. None $\triangle$ of the patients had serological evidence of recent infection with the other viruses tested for.

Confirmation that detection of anti-HPV IgM was not a false positive reaction caused by rheumatoid factors was obtained in two ways. Firstly, sera from two patients ( 1 and 3, Table 1) with anti-HPV IgM 0 and RF were absorbed with insoluble pooled human IgG coupled to Sepharose by cyanogen bromide. RF activity was bound to IgG and was subsequently eluted with $1 \mathrm{M}$ ammonia, whereas anti-HPV IgM activity did not bind and was recovered in the borate-saline eluate (Table 2). Secondly, the first $D$ serum sample from 21 RA patients contained RF (Table 3), but only two were anti-HPV IgM positive $N$ and their RF titres were $1 / 30$ and $>1 / 200$.

The prevalence of anti-HPV IgG which, in the $N$ absence of anti-HPV IgM, indicates past HPV $\mathrm{\omega}^{\mathrm{N}}$ infection was significantly higher in the patients with RA than in those with IA $(p<0.01)$ and in theo controls $(p<0.01)$ (Table 3$)$. The prevalence of $\Phi$ anti-HPV IgG in the patients with IA was slightly $\stackrel{?}{+}$ higher than that in the controls, but the difference $T$ was not significant $(p>0 \cdot 5)$. The mean age of the RA patients, however, was greater than that of $\cong$ 


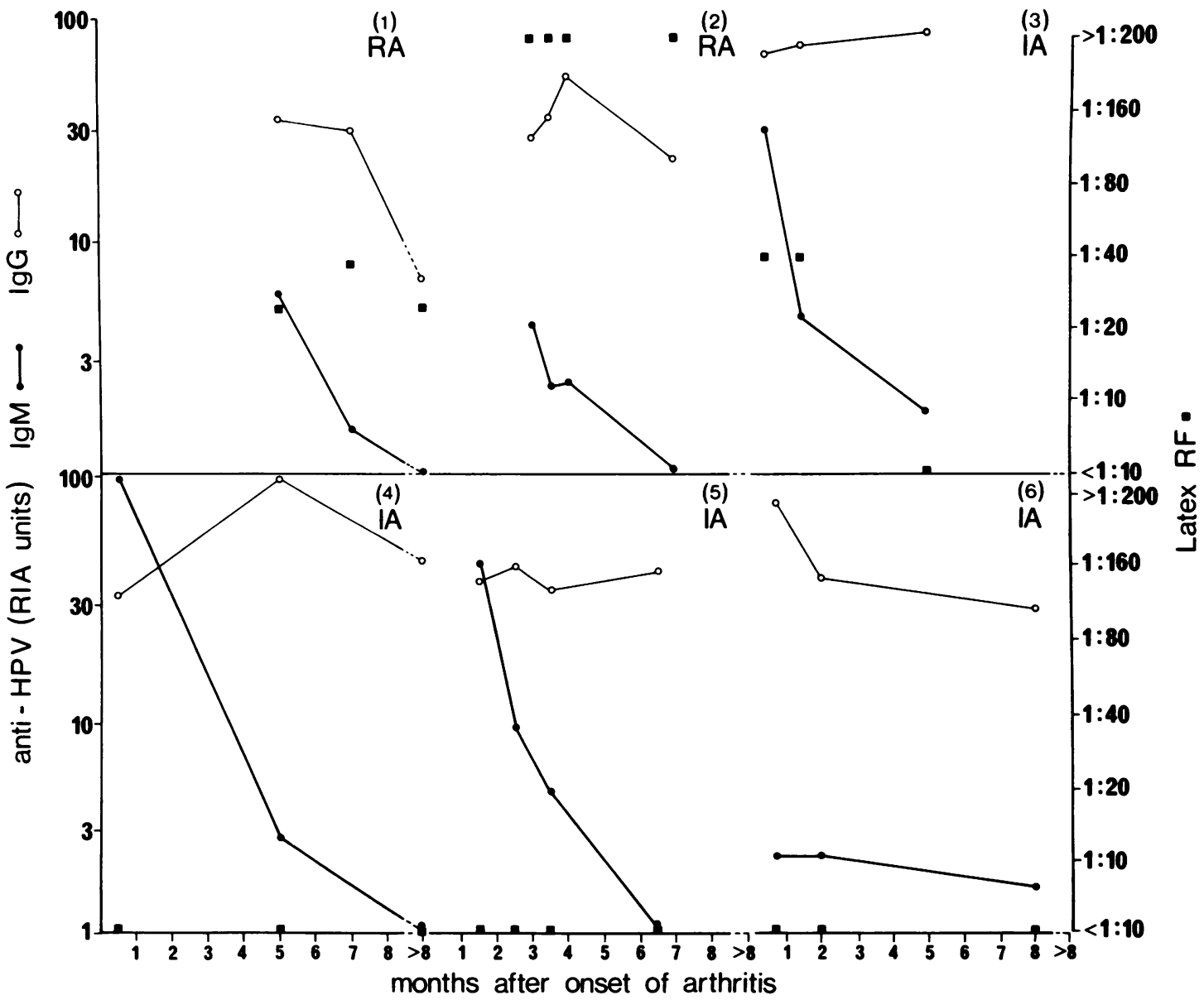

Fig. 1 Anti-HPV IgM, anti-HPV IgG and rheumatoid factor in two patients with rheumatoid arthritis and four patients with inflammatory arthritis.

Table 2 Absorption of anti-HPV IgM positive sera to remove $R F$ activity

\begin{tabular}{|c|c|c|c|c|}
\hline & \multicolumn{2}{|l|}{ Patient $1(R A)$} & \multicolumn{2}{|l|}{ Patient 3 (IA) } \\
\hline & $\begin{array}{l}\text { Anti-HPV IgM } \\
\text { (RIA units) }\end{array}$ & $\begin{array}{l}R F \\
\text { (titre) }\end{array}$ & $\begin{array}{l}\text { Anti-HPV IgM } \\
\text { (RIA units) }\end{array}$ & $\begin{array}{l}R F \\
\text { (titre) }\end{array}$ \\
\hline Original serum & $5 \cdot 2$ & $1 / 20$ & $5 \cdot 0$ & $1 / 40$ \\
\hline $\begin{array}{l}\text { Eluates from IgG: } \\
\text { borate-saline } \\
1 \mathrm{M} \mathrm{NH}\end{array}$ & $\begin{array}{l}3 \cdot 0 \\
\text { NT* }^{*}\end{array}$ & $\begin{array}{l}\text { Negative } \\
\text { Positive }\end{array}$ & $\begin{array}{l}1 \cdot 6 \\
\text { NT }\end{array}$ & $\begin{array}{l}\text { Negative } \\
\text { Positive }\end{array}$ \\
\hline $\begin{array}{l}\text { Eluates from } \mathrm{BSA}^{*} \text { : } \\
\text { borate-saline } \\
1 \mathrm{M} \mathrm{NH}_{3}\end{array}$ & $\begin{array}{l}3 \cdot 1 \\
\text { NT }\end{array}$ & $\begin{array}{l}\text { Positive } \\
\text { Negative }\end{array}$ & $\begin{array}{l}1 \cdot 5 \\
\text { NT }\end{array}$ & $\begin{array}{l}\text { Positive } \\
\text { Negative }\end{array}$ \\
\hline
\end{tabular}

${ }^{*} \mathrm{NT}=$ not tested; $\mathrm{BSA}=$ bovine serum albumin.

Sera $(0.25 \mathrm{ml}$ volumes) were applied to columns $(4 \times 0.7 \mathrm{~cm})$ of pooled human IgG-Sepharose and BSA-Sepharose and were eluted with borate-saline $\mathrm{pH} \mathrm{8.0}$ followed by $1 \mathrm{M} \mathrm{NH}_{3}$. Ammonia eluates were neutralised with $1 \mathrm{M}$ propionic acid before testing for RF activity but were too dilute to test for anti-HPV IgM activity. 
Table 3 Prevalence of anti-HPV IgG and rheumatoid factor in 39 patients with RA, 37 patients with IA, and 69 controls

\begin{tabular}{|c|c|c|c|c|}
\hline & \multirow[t]{2}{*}{$\begin{array}{l}\text { Age in years } \\
\bar{x} \text { (range) }\end{array}$} & \multirow[t]{2}{*}{$\begin{array}{l}\text { Anti-HPV IgG } \\
\text { number positive (\%) }\end{array}$} & \multicolumn{2}{|c|}{$\begin{array}{l}\text { Rheumatoid factor } \\
\text { number positive (\%) }\end{array}$} \\
\hline & & & First sample & Follow up \\
\hline \multirow{3}{*}{$\begin{array}{l}\text { Rheumatoid arthritis } \\
(\mathrm{n}=39 ; 15 \mathrm{M}, 24 \mathrm{~F}) \\
\text { Inflammatory arthritis } \\
(\mathrm{n}=37 ; 7 \mathrm{M}, 30 \mathrm{~F}) \\
\text { Controls } \\
(\mathrm{n}=69,21 \mathrm{M} 48 \mathrm{~F})\end{array}$} & \multirow{3}{*}{$\begin{array}{l}54 \cdot 8 \\
(16-79) \\
40 \cdot 2 \\
(17-76) \\
45 \cdot 2 \\
(19-75)\end{array}$} & $36(92 \cdot 3)$ & $21(53 \cdot 8)$ & $27(69 \cdot 2)$ \\
\hline & & $25(67 \cdot 6)$ & $2(5 \cdot 4)$ & $2(5 \cdot 4)$ \\
\hline & & $42(60 \cdot 9)$ & $4(5 \cdot 8)$ & \\
\hline
\end{tabular}

the controls, which in turn was greater than that of the patients with IA; but even when allowance for age was made anti-HPV IgG was significantly commoner in patients with RA than in controls. For example, in those more than 40 years old anti-HPV IgG was present in 30 of 31 RA patients and in 27 of 42 controls $(p<0 \cdot 01)$.

Neither HPV antigen nor DNA was found in any of the synovial fluids tested. Anti-HPV IgG was found in synovial fluids at levels that generally reflected the level of anti-HPV IgG in the corresponding serum (results not shown).

HLA haplotypes of the six patients with evidence of recent HPV infection are presented in Table 4. Both of the two patients with RA carried a haplotype associated with RA, namely Bw62 BfS C4A*3 C4B*3 DR4 and A2 B7 DR4. Of the four patients with IA, three had haplotypes which are not associated with RA, but the fourth (patient 3) carried the same RA associated haplotype as RA patient No 1, Bw62 BfS C4A*3 C4B*3 DR4. Moreover, the mother of patient No 3 also carried this haplotype and has severe classical RA.

A common haplotype, B7 BfS $\mathrm{C}_{4} \mathrm{~A}^{*} 3 \mathrm{C}^{\mathrm{B}} \mathrm{B}^{*} 1$ DR2, which is negatively associated with RA and may therefore act as protective haplotype against

Table 4 HLA haplotypes in six patients with evidence of recent $H P V$ infection

\begin{tabular}{|c|c|c|c|c|c|c|c|}
\hline \multirow[t]{2}{*}{ Patient } & \multicolumn{7}{|c|}{ Haplotypes in HPV positive patients } \\
\hline & $A$ & $B$ & $B f$ & $C 4 A$ & $C 4 B$ & $D R$ & $G L O$ \\
\hline \multirow[t]{2}{*}{1 (RA) } & 23 & w62 & $\mathrm{S}$ & 3 & 3 & 4 & 2 \\
\hline & 2 & 41 & $\vec{F}$ & 3 & 0 & 5 & 1 \\
\hline \multirow[t]{2}{*}{2 (RA) } & 2 & 7 & $\mathrm{~S}$ & 3 & 1 & 4 & 2 \\
\hline & 3 & 7 & $\mathrm{~S}$ & 3 & 1 & 2 & 1 \\
\hline \multirow[t]{2}{*}{3} & 3 & w62 & $\mathrm{S}$ & 3 & 3 & 4 & 2 \\
\hline & 2 & 49 & $\mathrm{~S}$ & 3 & 1 & 6 & 1 \\
\hline \multirow[t]{2}{*}{4} & 25 & 39 & $\mathrm{~S}$ & 3 & 2 & 7 & 2 \\
\hline & 3 & 7 & $\vec{S}$ & 3 & 1 & 2 & 2 \\
\hline \multirow[t]{2}{*}{5} & 1 & 44 & $\mathrm{~S}$ & 3 & 1 & 4 & 1 \\
\hline & 24 & 35 & $\mathbf{S}$ & 3 & 1 & 6 & 1 \\
\hline \multirow[t]{2}{*}{6} & 2 & 8 & $\mathbf{S}$ & 0 & 1 & 3 & 2 \\
\hline & 1 & w70 & S & 4 & 2 & 2 & 1 \\
\hline
\end{tabular}

the disease, was carried by both RA patient 2 and byg IA patient 4 .

\section{Discussion}

Definite serological evidence of recent HPV infec- $-\stackrel{\infty}{\omega}$ tion was found in three patients with inflammatory arthritis (patients 3, 4, and 5, Table 1 and Fig. 1). Anti-HPV IgM was present in high levels in acute $\overrightarrow{-}$ phase sera and fell to low levels or was absent in convalescent sera. Anti-HPV IgG levels in these three patients initially rose and then declined buto were still present eight months or more after onset of symptoms. One other patient with inflammatogyo arthritis (patient 6, Table 1 and Fig. 1) had om trace amounts of anti-HPV IgM in the acute phas but the pattern of falling levels of anti-HPV IgG in follow up sera was suggestive of recent infection. The clinical picture in these four patients was consistent with that described previously in HPVO arthropathy. ${ }^{2} 3$

Less definite evidence of recent HPV infection was found in two patients with rheumatoid arthritis (1 and 2, Table 1 and Fig. 1). They had only low? levels of anti-HPV IgM in the earliest availablew serum, but this disappeared from subsequent specio mens which, together with coincident changes ing anti-HPV IgG levels, indicated recent HPV infecis tion. Sera from these patients, however, containech high levels of rheumatoid factor and this is known to give rise to non-specific results when measuring virus specific IgM, though such reactions aro thought to be minimised with the 'antibody capture type assays used in this study. ${ }^{18}$ Since follow up seros from the same patients and other sera with high titres of RF were negative for anti-HPV IgM an\& since absorption with insoluble IgG removed RF buf not anti-HPV IgM activity from the sera of two patients it is considered that the results obtaine with these early rheumatoid sera represent true positive reactions for anti-HPV IgM. The low leve? of anti-HPV IgM more probably reflects the timing of the specimens, which were collected three and five months after the onset of symptoms. Fo? 
optimal diagnosis of HPV infection by demonstration of virus specific IgM it is necessary to examine a specimen collected no later than two to three months after onset of symptoms. ${ }^{10}$

Occurrence of an HPV infection at the onset of RA can be interpreted in several ways. The infection may have been coincidental reflecting the circulation of HPV infection in the general community. In this nine year survey evidence of recent HPV infection was found in only two years, 1980 (two cases) and 1985 (four cases). This may reflect the secular variations in the incidence of HPV infection, 1980 and 1985 being epidemic years for the infection in England (unpublished observations). Similar though larger clusters of HPV arthropathies were reported from another arthritis clinic in the west of England among patients seen in 1979 and $1980^{2}$ and from a clinic in the Grampian region of Scotland during a large HPV outbreak that occurred there in $1984 .^{3}$

The arthritogenic potential of HPV, which is greater than that of rubella for example, ${ }^{219}$ supports the alternative explanation for finding HPV infection at the onset of RA, namely that patients who are genetically predisposed to the disease are more likely to develop it after an arthritogenic insult such as an HPV infection. ${ }^{12}$ In murine models of systemic lupus erythematosus (SLE) three viruseslymphocytic choriomeningitis virus, polyoma virus, and retrovirus-induce or accelerate SLE-like disease and autoimmunity in genetically susceptible strains of mice. ${ }^{20}$ Both of our RA patients carry major histocompatibility complex (MHC) haplotypes associated with a risk of developing RA. In contrast, three of the four HPV infected IA patients have no RA associated haplotypes. One of these patients carries B44 DR4, which has been associated with RA in another study, ${ }^{21}$ but her extended haplotype, when her complotype is included, is not RA associated. ${ }^{15}$ The other patient carries a haplotype A3 B7 BfS C4A*3 C4B*1 DR2 considered to be protective against RA. The exception is IA patient 3 , who carries the haplotype strongly associated with RA in this region Bw62 BfS C4A*3 C4B*3 DR4. ${ }^{15}$ Moreover, she showed a transient rise in RF during the infection, and her mother, who also carries the same haplotype, has severe classical RA. Her infection, however, occurred only recently, in July 1985 , and it may be too soon for a reliable clinical prognosis. From our other studies this RA associated haplotype is more likely to be associated with autoimmunity expressed by rheumatoid factor together with the clinical features of RA than with susceptibility to the arthritogenic effects of an HPV infection. Tissue typing of more HPV infected patients is necessary to investigate this point.

The prevalence of anti-HPV IgG in patients with rheumatoid arthritis in this study $(92.3 \%)$ was significantly higher than that in controls $(60.9 \%)$. In a previous study by Lefrere and colleagues the prevalence of anti-HPV in rheumatoid arthritis patients $(33.3 \%)$ was also higher than in controls $(25.3 \%)$, but the difference was not considered significant. ${ }^{9}$ The difference in the prevalence of anti-HPV in their study and in ours can be explained in terms of the sensitivity of the assays used to measure the antibody. They used counterimmunoelectrophoresis, in which anti-HPV becomes undetectable 12 to 24 months after infection, ${ }^{22}$ whereas we used a more sensitive radioimmunoassay. It appears, therefore, that our series of rheumatoid arthritis patients contained an excess of subjects with a past exposure to HPV.

On the other hand, the higher prevalence of anti-HPV IgG in our rheumatoid arthritis patients could be due to the higher mean age of this group (54.8 years) compared with that of the controls (45.2 years). Although acquisition of antibody to HPV occurs principally in childhood between the ages of 6 and 10 years, ${ }^{23}$ there is a second, smaller peak of HPV infection between 30 and 40 years, and it seems likely that a continued gradual increase in the prevalence of anti-HPV IgG occurs with age. It is unlikely, however, that age accounts for the difference between our rheumatoid arthritis patients and controls because when only older subjects are considered (e.g., $>40$ years) the prevalence of anti-HPV IgG is still significantly higher in patients with rheumatoid arthritis than in controls.

The increased prevalence of anti-HPV IgG in our RA patients is reminiscent of the reported high titres of antibodies to Epstein-Barr virus (EBV) related antigens in RA. The increase in antibodies to EBV has been attributed to a defect in regulatory T lymphocytes, which are specific for EBV, and not to an overall defect in immunoregulatory $T$ cell function. ${ }^{24} \mathrm{~A}$ defect in HPV specific T lymphocytes might occur in RA patients and this warrants investigation. In contrast with the persistence of EBV infected cells in most RA patients and normal individuals there were no signs of persistent HPV infection in our RA or IA patients. No virus was detected in synovial fluids and the anti-HPV IgM response did not persist. These findings suggest that while HPV infection may be a triggering factor in rheumatoid arthritis in a genetically predisposed individual the virus is unlikely to have a continuing role in the pathogenesis of the disease. Moreover, the low incidence of HPV infection in our patients and, in a related study, ${ }^{12}$ the appearance of $R F$ at widely different times after onset of arthritic symptoms implies that there must be other agents involved in initiating the disease. 


\section{Addendum}

Recently we have tested an additional 74 patients ( 30 with RA and 44 with IA) for evidence of HPV infection at the onset of their arthritis. Two of the patients with RA and one with IA had detectable anti-HPV IgM and high levels of anti-HPV IgG within months of onset. These levels had fallen in follow up samples. Results for anti-HPV IgM in the two patients with RA were not false positives due to $\mathrm{RF}$; this possibility was excluded by first removing $\mathrm{RF}$ with solid phase IgG. Therefore, from a total of 69 patients with RA we now have evidence that four suffered a parvovirus infection at the onset of their rheumatoid arthritis.

This work was supported at the PHLS Virus Reference Laboratory by a grant from the Arthritis and Rheumatism Council and at the Royal Devon and Exeter Hospital by grants from the Northcott Devon Medical Foundation, the Wellcome Trust, and the Medical Research Council. We are grateful to Mrs E Williamson and Mr M Boyce for help with tissue typing.

\section{References}

1 Simpson R W. McGinty L. Simon L. Smith C A. Godzeski C W. Boyd R J. Association of parvoviruses with rheumatoid arthritis of humans. Science 1984; 224: 1425-8.

2 White D G, Woolf A D, Mortimer P P. Cohen B J, Blake D R. Bacon P A. Human parvovirus arthropathy. Lancet 1985; i: 419-21.

3 Reid D M, Reid T M S. Brown T. Rennic J A N. Eastmond C J Human parvovirus-associated arthritis: a clinical and laboratory description. Lancet 1985; i: 422-5.

4 Anderson M J. Jones S E. Fisher-Hoch S P. et al. Human parvovirus. the cause of erythema infectiosum (fifth disease)? Lancet 1983; i: 1378 .

5 Ager E A, Chin T D Y. Poland J D. Epidemic erythema infectiosum. N Engl J Med 1966; 275: 1326-31.

6 Anderson M J. Higgins P G, Davis L R. et al. Experimental parvoviral infection in humans. $J$ Infect Dis 1985: 152: 257-65.

7 Ropes M W, Bennett G A. Cobb S. Diagnostic criteria for rheumatoid arthritis. 1958 revision. Ann Rheum Dis 1959; 18: 49-53.
8 Luzzi G A. Kurtz J B. Chapel H. Human parvovirus arthro pathy and rheumatoid factor. Lancet $1985 ;$ i: 1218.

9 Lefrere J-J, Meyer O. Menkes C-J. Beaulieu M-M. Courouce. A-M. Human parvovirus and rheumatoid arthritis. Lancet i: 982 .

10 Cohen B J, Mortimer P P, Pereira M S. Diagnostic assays wiţ monoclonal antibodies for the human serum parvovirus-lik $\frac{\bar{E}}{\sigma}$ virus (SPLV). J Hyg (Lond) 1983: 91: 113-31.

11 Clewley J P. Detection of human parvovirus using a molect larly cloned probe. J Med Virol 1985: 15: 173-81.

12 Jones V E. Jacoby R K. Puttick A H. Cohen B J. Rheumatoid arthritis; a possible cause. clinical onset and appearance of rheumatoid factor. Arthritis Rheum (in press).

13 Jones V E. Jacoby R K. Wallington T B. Holt P. Immunecomplexes in early arthritis 1 . Detection of immune complexe before rheumatoid arthritis is definite. Clin Exp Immunol 1981尺 44: $512-21$

14 Jones V E. Taylor P C R. Jacoby R K, Wallington T B? Synovial synthesis of rheumatoid factors and immune comple constituents in early arthritis. Ann Rheum Dis 1984: 43: 235-9.

15 Puttick AH. Briggs D. Welsh K. Jacoby R K. Williamson ED Jones V E. Extended haplotypes in rheumatoid arthritis an $\otimes^{\circ}$ preliminary evidence for an interaction with immunoglobulin genes. Dis Markers (in press)

16 Awdeh Z L, Alper C A. Inherited structural polymorphism of the fourth component of human complement. Proc Natl Acad Sci USA 1980: 77: 3576-80.

17 Kömpf J. Bissbort S. Gussman S, Ritter H. Polymorphism of red cell glyoxalase-1 (EC:4.4.1.5). A new genetic marker if man. Humangenetik 1975; 27: 141-3.

18 Schmidt N. Update on class-specific viral antibody assays. Glin Immunol Newsletter 1984; 5: 81-5.

19 Anderson M J, Kidd I M. Morgan-Capner P. Human paro virus and rubella-like illness. Lancet 1985; ii: 663 .

20 Theofilopoulos A N. Dixon F J. Autoimmune diseasses Immunopathology and etiopathogenesis. Am J Pathol 1982 108: $321-65$.

21 Dyer P. Grennan D M. Walton K, et al. HLA and properdip factor (Bf) in rheumatoid arthritis [Abstract]. Ann Rheum Dis 1984: 43: 118 .

22 Anderson M J. Davis L R. Hodgson J. et al. Occurrence $0 \overrightarrow{5}$ infection with a parvovirus-like agent in children with sickle ce $\mathbb{B}$ anaemia during a two-year period. J Clin Pathol 1982; 35 744-9.

23 Edwards J M B. Kessel I, Gardner S D. et al. A search for a characteristic illness in children with serological evidence o. viral or toxoplasma infection. J Infection 1981; 3: 316-23. ㅇ.

24 Tosato G. Blaese $R$ M. Epstein-Barr virus infection and immunoregulation in man. Advan Immunol 1985; 37: 99-149ב 